\title{
PEMBERDAYAAN MASYARAKAT SEBAGAI WUJUD TANGGUNG JAWAB SOSIAL PERUSAHAAN (STUDI KASUS PT. TIRTA INVESTAMA PLANT SOLOK) DI NAGARI BATANG BARUS KABUPATEN SOLOK
}

\author{
Yulia Risa \\ yuliarisa24@gmail.com \\ Program Ilmu Hukum Universitas Dharma Andalas
}

\begin{abstract}
ABSTRAK
Penelitian ini bertujuan untuk melaporkan keterlibatan dan pelaksanaan pertanggung jawaan sosial (Corporate Social Responsibility) PT. Tirta Investama Pabrik Aqua Plant Solok dalam pemberdayaan masyarakat di Nagari Batang Barus Kabupaten Solok. Dengan melaksanakan Corporate Social Responsibility (CSR), maka perusahaan tidak hanya mengutamakan kondisi keuangan perusahaan (single bottom line), tetapi juga memperhatikan konsep pembangunan yang berkelanjutan dan bermanfaat bagi pemberdayaan masyarakat, yakni prinsip dasar sosial, lingkungan, dan etika (tripel bottom line). Penelitian ini merupakan penelitian deskriptif analitis dengan jenis data kualitatif. Metode penelitian yang digunakan yakni penelitian yuridis empiris. Data primer pada penelitian ini diperoleh dari wawancara, observasi dan studi lapangan, kemudian dianalisis dengan undangundang, teori dan pendapat pakar yang relevan, sedangkan data sekunder yang diperoleh dari berbagai literatur dan peraturan perundang-undangan. Berdasarkan hasil penelitian ini ditemukan bahwa semenjak tahun 2014 pelaksanaan pertanggung jawaban sosial PT. Tirta Investama Danone Aqua dilaksanakan oleh lembaga swadaya masyarakat (LSM) Perkumpulan Keluarga Berencana Indonesia (PKBI) Provinsi Sumatera Barat dan Yayasan Field Indonesia. Kegiatan pertanggung jawaban sosial dilaksanakan dalam bentuk program pemetaan sosial, pembuatan fasilitas air bersih dan sanitasi. Pada bidang ekonomi, kegiatan yang dilakukan yakni program sekolah lapangan alpukat, sedangkan dalam bidang lingkungan, PT. Tirta Investama Danone Aqua membangun Taman Keanekaragaman Hayati (KEHATI) dan Program Sanitasi Total Berbasis Masyarakat. Kedua Keterlibatan CSR PT. Tirta Investama dalam pemberdayaan Masyarakat di Nagari Batang Barus adalah melalui Program Sanitasi Total Berbasis Masyarakat (STBM).
\end{abstract}

Kata kunci : pemberdayaan masyarakat; tanggung jawab sosial perusahaan. 


\title{
COMMUNITY EMPOWERMENT AS THE COMPANY'S SOCIAL RESPONSIBILITY OF THE COMPANY \\ (CASE STUDY OF PT. TIRTA INVESTAMA PLANT SOLOK) IN NAGARI BATANG BARUS, SOLOK DISTRICT
}

\author{
Yulia Risa \\ yuliarisa24@gmail.com \\ Law Program of Dharma Andalas University
}

\begin{abstract}
This study aims to report the involvement and the implementation of Corporate Social Responsibility (CSR) of PT. Tirta Investama Plant Solok as an effort to empower the community in Nagari Batang Barus, Solok Regency. By implementing the CSR, the corporate proved that they are not only prioritizing the corporate's economic condition, but also realizing the importancy of giving contribution to the community referred to the sustainability principles (social, environmental, and ethics) as an effort to balance environment and nature (Sustainable development). By paying attention to CSR, the company is not only oriented to corporate finance (single bottom line) but focuses on the balance between financial, social and environmental aspects (triple bottom line).The synergy of these three keys is the concept of sustainable development and community empowerment. This research is a descriptive analytical research with qualitative data. This study uses a sociological juridical research method to see how companies engaged in natural resources apply CSR strategies and principles in their business activities in realizing community empowerment around the company. The primary data obtained through interviewing, observing, and studying the location, then the data are being analyzed according to the law, theory and the opinion of the experties. Meanwhile the secondary data obtained from literatures and legislation. The results of the study illustrate the strategic steps taken by PT. Tirta Investama Solok Plant is entrusted to NGOs (Non-Government Organizations), namely the Partners of the Indonesian Family Planning Association (PKBI) of the Province of West Sumatra and the Field of Indonesia Foundation since 2014. The involvement of CSR PT. Tirta Investama Solok Plant in Community Empowerment in Nagari Batang Barus was carried out in the social planning and the Satinasi Total Berbasis Masyarakat (STBM) program. Meanwhile in economic sector, the corporate conducted an avocado schoolfield, amd in environmental sector, the corporate build Taman Keanekaragaman Hayati (KEHATI) dan Program Sanitasi Total Berbasis Masyarakat.
\end{abstract}

Keyword: Community Empowerment; Corporate Social Responsibility. 
e-ISSN : 2621-4105

\section{A. PENDAHULAN}

Dalam konteks global, istilah Corporate Social Responsibility (CSR) mulai digunakan sejak tahun 1970-an dan semakin populer terutama setelah kehadiran buku Cannibals With Forks: The Triple Bottom Line in 21st Century Business (1998), karya John Elkington. (Marnelly 2012). John Elkingston's mengelompokkan CSR atas tiga aspek berkaitan dengan peningkatan kesejahteraan stakeholders dengan memperhatikan lingkungan ke arah yang lebih baik, yang dikenal dengan istilah Triple Bottom Line (3BL). Ketiga aspek tersebut meliputi kesejahteraan atau kemakmuran ekonomi (economic prosperity), peningkatan kualitas lingkungan (environmental quality), dan keadilan sosial (social justice). Lebih lanjut, ia menegaskan bahwa suatu perusahaan yang ingin menerapkan konsep pembangunan berkelanjutan (sustainable development) harus memerhatikan Triple Pyaitu profit, planet, and people. Apabila dikaitkan antara 3BL dengan Triple $\mathrm{P}$ dapat disimpulkan bahwa profit sebagai wujud aspek ekonomi, dan planet sebagai wujud aspek lingkungan, serta peoplesebagai aspek sosial. $^{1}$

Perusahaan tidak akan bertahan lama bila hanya mementingkan dan mengandalkan keuntungan semata. Maka dari itu lingkungan dan masyarakat wajib diikut sertakan dalam keberlangungan perusahaan itu sendiri akan tetapi bisa saja perusahaan tidak melakukan program CSR apabila tidak ada hukum yang mengatur. Untung saja sudah ada undang-undang yang mengatur kewajiban CSR bagi perusahaan lebih lanjut dikembangkan dalam UUPT beserta peraturan pelaksananya yakni Peraturan Pemerintah Nomor 47 Tahun 2012 tentang Tanggung Jawab Sosial dan Lingkungan Perseroan Terbatas (selanjutnya disebut PP CSR). Pasal 74 UUPT yang berbunyi sebagai berikut:

\footnotetext{
${ }^{1}$ Zain, Qurratie. 2015. "Collaboration Strategy dalam Implementasi Corporate Social Responsibility (CSR): Studi Kasus Aqua Danone Klaten.” Jurnal Hubungan Internasiona VIII(2): 81-98.
} 
1. Perseroan yang menjalankan Kegiatan usahanya di bidang dan/atau berkaitan dengan sumber daya alam wajib melaksanakan tanggung jawab sosial dan lingkungan.

2. Tanggung Jawab sosial dan lingkungan sebagaimana dimaksud pada ayat (1) merupakan kewajiban perseroan yang dianggarkan dan diperhitungkan sebagai biaya perseroan yang pelaksanaannya dilakukan dengan memperhatikan kepatutan dan kewajaran.

3. Perseroan yang tidak melaksanakan kewajiban sebagaimana dimaksud ayat (1) dikenai sanksi sesuai dengan ketentuan peraturan perundang-undangan.

4. Ketentuan lebih lanjut mengenai Tanggung Jawab sosial dan lingkungan diatur dengan Peraturan Pemerintah.

Pelaksanaan CSR oleh perusahaan pengelola SDA belum sesuai antara idealita (harapan) dan realitas, karena ada resistensi dari perusahaan atas kewajiban CSR oleh hukum, tidak semua perusahaan dengan penuh ketaatan untuk melaksanakannya. Disisi lain UUPT, Peraturan Pemerintah Nomor 47 tahun 2012 tentang Tanggung Jawab Sosial dan Lingkungan Perseroan, dan belum mengatur mekanisme penerapan CSR secara komfrehensif. ${ }^{2}$

Masih banyak perusahaan tidak mau menjalankan programprogram CSR karena melihat hal tersebut hanya sebagai pengeluaran biaya (cost center). CSR memang tidak memberikan hasil secara keuangan dalam jangka pendek. Namun CSR akan memberikan hasil baik langsung maupun tidak langsung pada keuangan perusahaan di masa mendatang. Dengan demikian apabila perusahaan melakukan program-program CSR diharapkan keberlanjutan perusahaan akan terjamin dengan baik. Oleh karena itu, programprogram $C S R$ lebih tepat apabila digolongkan sebagai investasi dan harus menjadi strategi bisnis dari suatu perusahaan, dengan masuknya program CSR sebagai bagian dari strategi bisnis, maka akan dengan mudah bagi unit-unit usaha yang berada dalam suatu perusahaan untuk mengimplementasikan rencana kegiatan dari

${ }^{2}$ Firdaus. 2017. "Normativiitas Corporate Social Responsibility Antara Idealita Dan Realitas.” Jurnal Ilmu Hukum 4(1). 
program CSR yang dirancangnya. Dilihat dari sisi pertanggung jawaban keuangan atas setiap investasi yang dikeluarkan dari program $C S R$ menjadi lebih jelas dan tegas, sehingga pada akhirnya keberlanjutan yang diharapkan akan dapat terimplementasi berdasarkan harapan semua stakeholder.

Begitupun halnya Pemerintah Provinsi Sumatera Barat dengan lahirnya Peraturan Daerah Nomor 7 Tahun 2015 tentang Tanggung Jawab Sosial dan Lingkungan. Dengan adanya payung hukum di Sumatera Barat untuk mengatur tanggung jawab sosial dan lingkungan perusahaan maka pemerintah daerah dapat mengetahui program-program CSR yang dilakukan baik BUMN, BUMD maupun perusahaan lainnya yang ada di Sumatera Barat akan terjalin komunikasi dan sinergi antara Pemerintah dengan perusahaan yang membuat program CSR tepat sasaran dan tidak tumpang tindih.

Nagari Batang Barus terletak di pusat Ibukota Kabupaten Solok yang berada di lereng Gunung Talang dengan jarak $\pm 5 \mathrm{~km}$ dan berbatas langsung dengan Kota Padang. Nagari Batang Barus berdampingan dengan Nagari Koto Gaek, Nagari Koto Gadang Guguak dan Nagari Aia Batumbuak. Jumlah penduduk 7.833 jiwa yang terdiri dari 3984 jiwa laki-laki, dan 3849 jiwa perempuan. Umumnya mata pencaharian penduduk di Nagari Batang Barus adalah pertanian,serta di Jorong Kayu Jao juga terdapat perkebunan Teh. Dengan topografi berbukit dan berlembah karena terletak di gugusan Bukit Barisan, nagari ini adalah sebuah kawasan pertanian, perdagangan, perkantoran, serta kawasan wisata karena diberkahi oleh Sang Pencipta dengan alamnya yang indah dan lahan yang subur.

Menyebut kata "aqua" bagi masyarakat Indonesia adalah menyebut produk air minum dalam kemasan (AMDK) apapun, tanpa memandang nama merek sebenarnya. Berbagai merk kemasan air minum di Indonesia belum mampu menggeser kuatnya branding dari aqua. Aqua adalah merek AMDK dengan penjualan terbesar di Indonesia dan merupakan salah satu merek AMDK yang paling terkenal di Indonesia dan untuk memenuhi kebutuhan air minum yang sehat dan berkualitas bagi Masyarakat Sumatera Barat.

Tahun 2013 PT. Tirta Investama plant Aqua Kayu Aro merupakan perusahaan AQUA Grup mendirikan pabrik yang ke-17 di Indonesia, yang 
berlokasi di Jorong Kayu Aro, Kanagarian Batang Barus, Kecamatan Gunung Talang, Kabupaten Solok. AQUA telah hadir di Indonesia sejak tahun 1973, dengan misi untuk memberikan kesehatan kepada masyarakat Indonesia melalui produk minuman yang sehat dan berkualitas.

Dalam survey penulis PT. Tirta Investama plant Aqua merupakan perusahaan yang bergerak dibidang penyediaan AMDK, konsep CSR ini menjadi penting bagi perusahaan tersebut karena bergerak di bidang pengolahan sumber daya alam karena berdiri berdampingan secara langsung dengan masyarakat sekitar. Sehingga sebagai perusahaan yang bertanggung jawab menjadi kewajiban dalam pemberdayaan dan pembangunan masyarakat.

Ketersediaan air untuk keberlangsungan usaha perusahaan sangat dipengaruhi oleh kondisi lingkungan sumber air yang tidak terlepas dari keberadaan masyarakat yang tinggal dalam radius tertentu di sekitarnya yang merupakan bagian dari lingkungan itu sendiri. Perusahaan menyadari pentingnya keseimbangan antara sumber air, perusahaan dan masyarakat di lingkungan sekitar sebagai salah satu syarat terciptanya pertumbuhan berkelanjutan. Perusahaan berkomitmen menjalankan berbagai kegiatan atau program dalam rangka menciptakan keseimbangan serta wujud Tanggung Jawab Sosial Perusahaan. Perusahaan sudah menerapkan pendekatan berbasis masyarakat dalam menjalankan program-program sosialnya dengan melakukan kemitraan dengan masyarakat, pemerintah daerah dan para pemangku kepentingan yang lain.

Dalam pengembangan implementasi CSR, PT. Tirta Investama Plant Solok melibatkan beberapa NGO untuk pelaksanaan program di Kanagarian Batang Barus diantaranya Perkumpulan Keluarga Berencana Indonesia (PKBI), yang merupakan Lembaga Swadaya Masyarakat (LSM) yang bergerak dibidang kesehatan reproduksi dan keluarga berencana, Field Indonesia dan WARSI. Dalam konteks ini, NGO diartikan sebagai pelaksana, pendamping, pembimbing dan pengontrol program CSR hingga tujuan dapat tercapai.

Bermacam program CSR berbasis sosial dan lingkungan telah dilaksanakan PT. Tirta Investama pada masyarakat, diaktualisasikan dalam AQUA Lestari yang dikembangkan sejak tahun 2006 sebagai payung inisiatif keberlanjutan dengan 
menggunakan DANONE WAY dan ISO 26000 sebagai referensi. AQUA Lestari direalisasikan dengan melaksanakan berbagai inisiatif sosial dan lingkungan yang mencakup wilayah sub-Daerah Aliran Sungai (DAS) secara terintegrasi dari wilayah hulu, tengah, dan hilir di lokasi AQUA Group beroperasi yang disesuaikan dengan konteks lokal. Berbagai inisiatif tersebut berada di bawah empat pilar, yaitu: Pelestarian Air dan Lingkungan, Praktik Perusahaan Ramah Lingkungan, Pengelolaan Distribusi Produk, serta Perlibatan dan Pemberdayaan Masyarakat.

\section{B. PERMASALAHAN}

Berangkat dari permasalahan di atas, diharapkan CSR PT. Tirta Investama Plant Solok untuk memberdayakan masyarakat di Kanagarian Batang Barus Kabupaten Solok kepada masyarakat yang mandiri dan apakah tanggung jawab sosial perusahaan dan lingkungan perusahaan tersebut telah dianggap memenuhi ukuran dalam mengamalkan Pasal 74 ayat 1 UUPT dan implementasinya demi mewujudkan pengembangan ekonomi yang berkelanjutan sebab dengan memperhatikan CSR maka perusahaan tidak hanya berorientasi kepada keuangan perusahaan semata (single bottom line) akan tetapi menitik beratkan pada keseimbangan antara aspek keuangan, aspek social dana aspek lingkungan (tripel bottom line) sinergi dari ketiga kunci ini merupakan konsep pembangunan yang berkelanjutan dan pemberdayaan masyarakat. Berdasarkan latar belakang dan problematika yang muncul tersebut di atas maka dapat dirumuskan permasalahan sebagai berikut: Bagaimanakah pelaksanaan CSR oleh PT. Tirta Investama plant Solok di Nagari Batang Barus Kabupaten Solok dan Bagaimanakah keterkaitan CSR PT. Tirta Investama Plant Solok dalam upaya pemberdayaan masyarakat di Nagari Batang Barus Kabupaten Solok.

\section{METODE PENELITIAN}

Untuk menjawab permasalahan yang telah dirumuskan dalam penelitian ini, digunakan metode pendekatan yuridis sosiologis (empiris) yaitu penelitian yang berlandaskan pada kaidah-kaidah hukum yang dilihat dari segi penerapannya. ${ }^{3}$ Melalui penelitian Yuridis Sosiologis (empiris) ini dapat dilihat bagaimana

\footnotetext{
${ }^{3}$ Soerjono Soekanto, Purnadi Purbacaraka. 1979. Perihal Penelitian Hukum. Bandung: Alumni.hal 21
} 
perusahaan yang bergerak di bidang Air Minum dalam Kemasan menerapkan prinsip-prinsip Coorporate Social Responsibility dalam aktivitas usahanya. Namun sebelum melihat penerapannya, terlebih dahulu juga dipahami tentang pengaturan prinsip-prinsip CSR yang berkaitan dengan ketentuan peraturan perundangundangan.

Penulisan ini didasarkan pada beberapa teori untuk dijadikan landasan dalam upaya menjawab masalah utama penelitian sebagaimana disebutkan pada rumusan masalah dengan mengunakan 2 (dua) pendekatan teori, yaitu: Teori pemberdayaan masyarakat dan prinsip tanggung jawab sosial perusahaan dan esensi pengaturannya dalam Undang-undang Nomor 19 tahun 2003 tentang Badan Usaha Milik Negara, Undang-undang Nomor 40 tahun 2007 tentang Perseroan Terbatas, dan Undang-undang Nomor 25 Tahun 2007 tentang Pasar Modal dan Peraturan Daerah Sumatera Barat Nomor 15 Tahun 2017 tentang Tanggung Jawab Sosial Perusahaan dan Lingkungan. Kedua Teori Tanggung Jawab Sosial Perusahaan untuk menganalisa permasalahan yang berkaitan penerapan tanggung jawab sosial perusahaan dan dalam pelaksanaan CSR pada PT. Tirta Investama Plant Solok terhadap Masyarakat di Nagari Batang Barus Kabupaten Solok.

Penelitian ini bersifat deskriptif analitis, yang mengungkapkan peraturan perundang-undangan yang berkaitan dengan teori-teori hukum yang menjadi objek penelitian. Demikian juga hukum dalam pelaksanaannya didalam masyarakat yang berkenaan objek penelitian. ${ }^{4}$ Penelitian ini diharapkan dapat diperoleh gambaran yang menyeluruh dan lengkap mengenai pelaksanaan Coorporate social Responsibility pada PT. Tirta Investama Plant Solok dan keterkaitannyaa dengan pemberdayaan masyarakat setempat.

\section{LANDASAN TEORITIS}

Penulisan ini didasarkan pada beberapa teori untuk dijadikan landasan dalam upaya menjawab masalah utama penelitian sebagaimana disebutkan pada rumusan masalah dengan mengunakan 2 (dua) pendekatan teori, yaitu: Teori Tanggung Jawab Sosial Perusahaan untuk menganalisa permasalahan yang

${ }^{4}$ Ali, Zainudin. 2010. Metode Penelitian Hukum. Jakarta: Sinar Grafika. 
berkaitan penerapan tanggung jawab sosial perusahaan dan dalam pelaksanaan CSR pada PT. Tirta Investama Danone Aqua terhadap Masyarakat di Kanagarian Batang Barus Kabupaten Solok. Kedua Teori pemberdayaan masyarakat

\section{Teori Tanggung Jawab Sosial ( Social Responsibility Theory}

Konsep Tanggung Jawab Sosial Perusahaan atau CSR telah mulai dikenal sekitar tahun 1970-an dan umumnya CSR diartikan sebagai kumpulan kebijakan dan praktek yang berhubungan dengan stakeholders, nilai-nilai, pemenuhan ketentuan hukum, penghargaan masyarakat dan lingkungan, serta komitmen perusahaan untuk memberikan kontribusi dalam pembangunan berkelanjutan. Bank Dunia mendefinisikan CSR sebagai komitmen perusahaan untuk memberikan kontribusi pengembangan ekonomi secara berkelanjutan, untuk bekerja bersama karyawan serta keluarga mereka, masyarakat lokal dan masyarakat keseluruhan untuk meningkatkan kualitas hidup menjadi lebih baik, sehingga baik untuk bisnis dan pembangunan. Pada dasarnya konsepsi terhadap tanggung jawab sosial tidak jauh berbeda dengan konsep tanggung jawab pada umunya. Perbedaannya hanya terletak pada sudut pandangnya saja.

Menurut Busyra Azheri Teori tanggung jawab lebih menekankan pada makna tanggung jawab yang lahir dari ketentuan peraturan perundang-undangan, sehingga teori tanggung jawab lebih dmaknai dalam arti liability sedangkan teori tanggung jawab sosial (sosial responsibility theory) sendiri lahir dari kebebasan positif yang menekankan tanggung jawab dalam makna responsibility. Filosofi utama dari teori tanggung jawab sosial sungguh radikal karena dibatasi kebebasan dalam makna positif. Tapi dalam prakteknya teori ini sangat familiar, karena responsibility itu sendiri berarti keadaan yang dapat dipertanggung jawabkan, dimana keadaan yang dipertanggungjawabkan itu membutuhkan campur tangan negara, sebagai yang ditunjukan dalam sejarah kaum libertarian

\section{Teori Pemberdayaan Masyarakat}

Secara etimologis pemberdayaan berasal dari kata dasar "daya" yang berarti kekuatan atau kemampuan. Bertolak dari pengertian tersebut maka pemberdayaan dapat dimaknai sebagai suatu proses menuju berdaya, atau proses untuk memperoleh daya/ kekuatan/ kemampuan, dan atau proses pemberian daya/ 
kekuatan/ kemampuan dari pihak yang memiliki daya kepada pihak yang kurang atau belum berdaya.

Menurut Oos M. Anwas Secara konseptual, pemberdayaan atau pemberkuasaan (empoerment), berasal dari kata 'power' (kekuasaan atau keberdayaan). Istilah kekuasaan sering kali indentik dengan kemampuan individu untuk membuat dirinya atau pihak lain melakukan apa yang di inginkannya. Kemampuan tersebut baik untuk mengatur dirinya, mengatur orang lain sebagai individu dan kelompok/ organisasi, terlepas dari kebutuhan, potensi, atau keinginan orang lain.

Pemberdayaan menunjuk pada kemampuan orang, khususnya kelompok rentan dan lemah sehingga mereka memiliki kekuatan atau kemampuan dalam (a) memenuhi kebutuhan dasarnya sehingga mereka memiliki kebebasan (freedom), dalam arti bukan saja bebas mengemukakan pendapat, melainkan bebas dari kelaparan, bebas dari kebodohan, bebas dari kesakitan, (b) menjangkau sumbersumber produtif yang memungkinkan mereka dapat meningkatkan pendapatannya dan memperoleh barang-barang dan jasa-jasa yang mereka perlukan; dan (c) berpartisipasi dalam proses pembangunan dan keputusan-keputusan yang mempengaruhi mereka. Beberapa ahli dibawah ini mengemukakan definisi pemberdayaan dilihat dari tujuan, proses, dan cara-cara pemberdayaan:

1. Pemberdayaan bertujuan untuk meningkatkan kekuasaan orang-orang yang lemah atau tidak beruntung.

2. Pemberdayaan adalah sebuah proses dengan mana orang menjadi cukup kuat untuk berpartisipasi dalam, berbagi pengontrolan atas, dan mempengaruhi terhadap, kejadian- kejadian serta lembaga-lembaga yang mempengaruhi kehidupannya. Pemberdayaan menekankan bahwa orang memperoleh keterampilan, pengetahuan, dan kekuasaan yang cukup untuk mempengaruhi kehidupannya dan kehidupan orang lain yang menjadi perhatiannya.

3. Pemberdayaan menunjuk pada usaha pengalokasian kembali kekuasaan melalui pengubahan struktur sosial. 
4. Pemberdayaan adalah suatu cara dengan mana rakyat, organisasi, dan komunitas diarahkan agar mampu menguasai (berkuasa atas) kehidupannya.

Meskipun pembedayaan masyarakat bukan semata-mata konsep ekonomi, tetapi seringkali di tujukan untuk tujuan pengentasan kemiskinan dan kesejahteraan masyarakat. Kegiatan pemberdayaan tersebut dilakukan melalui berbagai kegiatan yang dapat mendorong kemampuan dan keterampilan yang sesuai dengan potensi dan kebutuhan masyarakat setempat, menciptakan berbagai kesempatan kerja, menghidupkan kembali buadaya dan kearifan -kerarifan lokal

\section{E. PEMBAHASAN}

\section{Pelaksanaan CSR oleh PT. Tirta Investama Plant Aqua Di Nagari Batang Barus Kabupaten Solok.}

Peraturan Daerah Nomor 7 Tahun 2015 tentang Tanggung Jawab Sosial dan Lingkungan di Sumatera Barat.Pasal 1 angka 4 Tanggung Jawab Sosial dan Lingkungan Perusahaan yang selanjutnya disingkat TJSLP adalah komitmen perusahaan untuk berperan serta dalam pembangunan ekonomi berkelanjutan guna meningkatkan kualitas kehidupan dan lingkungan yang bermanfaat, baik bagi perusahaan, komunitas setempat maupun masyarakat pada umumnya.walaupun dalam perda ini ada diatur mengenai sanksi namun apabila dalam peraturan perundang-undang yang lebih tinggi tidak mengatur sanksi maka berlaku asas dimana aturan yang lebih tinggi tidak boleh bertentangan dengan aturan yang di bawahnya, artinya sanksi tersebut pun punya celah untuk tidak di berlakukan.

Jika dilihat dari peraturan diatas, urusan terkait dengan CSR merupakan domain pemerintah pusat, karena baik Peraturan Menteri BUMN, Undang-Undang PT, Undang-Undang PMA, Undang-Undang Minyak dan Gas Bumi dibuat oleh DPR bersama Pemerintah Pusat. Sedangkan peran pemerintah daerah adalah melakukan monitoring dengan perangkat Analisis Mengenai Dampak Lingkungan dan Sosial (Amdalsos) dan Perda mengkaji sejauhmana perusahaan mampu memberikan manfaatnya kepada stakeholder dalam hal ini masyarakat setempat. Sudah seharusnya terjadi perubahan paradigma perusahaan agar tidak hanya mengedepankan kepentingan memperoleh laba semata-mata, namun juga 
keberadaan perusahaan mampu memberikan kesejahteraan masyarakat sekitar seiring dengan mendukung adanya good governance. Begitupun pada PT. Tirta Investama plant Solok yang lebih dikenal masyarakat luas dengan nama AQUA, merupakan perusahaan yang bergerak dalam produksi dan penyediaan Air Minum Dalam Kemasan (AMDK) yang sehat dan berkualitas bagi seluruh lapisan masyarakat. AQUA memiliki beberapa cabang pabrik di Indonesia, salah satunya pabrik Solok (Plant Solok) yang merupakan pabrik yang ke 14.

AQUA Plant Solok yang berlokasi di Jl. Raya Padang-Solok Km 37, Jorong Kayu Aro, Nagari Batang Barus, Kecamatan Gunung Talang, Kabupaten Solok yang telah beroperasi sejak 2013 dan didirikan oleh Danone. Plant Solok ini menempati lahan seluas 9.23 Ha. AQUA Plant Solok ini memproduksi air kemasan berukuran $600 \mathrm{ml}$ dan galon (18 liter/galon).Sumber air yang digunakan oleh AQUA berasal dari air bawah tanah.

Pelaksanaan Tanggung jawab sosial perusahaan AQUA Group berawal dari pemikiran Riboud, tentang komitmen ganda perusahaan. Komitmen ganda merupakan cara menjalankan bisnis yang mengedepankan keseimbangan antara keberhasilan ekonomi dan kemajuan sosial. Pemikiran tersebut sejalan dengan pemikiran pendiri AQUA, Tirto Utomo, yang berprinsip bahwa bisnis harus berkontribusi sosial pada masyarakat.

Pelaksanaan CSR oleh PT. Tirta Investama Pabrik Aqua sudah dilakukan sejak tahun 2010 jauh sebelum perusahaan didirikan bentuk strategi CSR yang dilakukan di Nagari Batang Barus dapat dikelompokkan kedalam 4 (empat) bidang:

\section{Di bidang sosial.}

a. Pemetaan Sosial.

Bentuk kegiatan yang dilakukan di bidang sosial ini adalah pemetaan sosial (social mapping) Nagari Batang Barus, kegiatan ini dilakukan dari bulan Maret hingga Juli 2017 di Nagari Batang Barus, Kacamatan Gunung Talang, Kabupaten Solok. Pemetaan sosial adalah langkah awal untuk melihat situasi dan keadaaan Nagari Batang Barus Kegiatan Pemetaan Sosial ini bertujuan adalah:

a) untuk memperoleh informasi mengenai komposisi pemangku kepentingan perusahaan, 
b) Memperoleh informasi mengenai isu, masalah dan potensi lingkungan nagari dan masyarakat

c) Memperoleh informasi mengenai kebutuhan dan peluang pengembangan masyarakat berdasarkan kondisi local

d) Memperoleh rekomendasi untuk pengembangan program sosial dan lingkungan yang sejalan kebutuhan masyarakat dan misi perusahaan

2. Di Bidang Ekonomi

a. Konservasi Berbasis Masyarakat (sekolah Lapangan Alpukat).

Bentuk kegiatan dalam bidang ekonomi yang dilakukan oleh PT. Tirta Investama Pabrik Aqua berupa Konservasi Berbasis Masyarakat (Sekolah Lapangan Alpukat) kegiatan ini dilaksankan sejak bulan Juli 2015 yang lalu, Yayasan FIELD Indonesia sebagai salah satu mitra pelaksana program tanggung jawab sosial perusahaan (CSR) pabrik AQUA Solok telah mendampingi warga belajar di Jorong Kayu Aro untuk belajar bersama tentang pertanian berkelanjutan.

Menurut Koordinator CSR Tirta Investama pabrik Aqua Solok, Jon Betritpabrik Aqua Solok menurutnya telah mendampingi warga belajar di Jorong Kayu Aro untuk belajar bersama tentang pertanian berkelanjutan. Sekolah Lapangan (SL) adalah suatu bentuk proses belajar masyarakat yang berkumpul sekali seminggu untuk mengikuti proses belajar. Bentuk yang dilakukan oleh warga belajar seperti menganalisa perkembangan tanaman dari fase demi fase serta mendalami berbagai prinsip terkait perkembangan dinamika tanaman akibat faktor alam seperti populasi serangga, fisiologi dan kompensasi tanaman, pemeliharaan kesuburan tanah, pengaruh air dan cuaca, pemilihan varietas, dan lain-lain, melalui eksperimen-eksperimen yang mereka lakukan sendiri. Selanjutnya kegiatan pokok, dilakukan adalah untuk memitigasi masalah-masalah yang dihadapi masyarakat. Dalam proses ini diharapkan masyarakat dapat berpartisipasi secara penuh dalam belajar dan pengambilan keputusan.

\section{Di Bidang Lingkungan}

Kontribusi PT. Tirta Investama Plant Solok, selanjutnya adalah Membangun Taman Keanekaragaman Hayati (Kehati) 2014 - Sekarang, Taman Kehati atau Taman Kota adalah salah satu program yang dikembangkan oleh semua 
pabrik AQUA plan solok. Tujuan utama program pengembangan Taman Kehati ini adalah sebagai sarana ruang terbuka hijau, sebagai koleksi tumbuhan endemik lokal, sebagai kawasan konservasi in-situ dan ex-situ guna menyelamatkan dan mengembangkan berbagai jenis flora dan fauna.Selain itu keragaman hayati juga berfungsi untuk mendukung sistem kehidupan seperti penjaga kualitas tanah, penyimpanan air tanah dan menjaga siklus karbon dan nutrisi.Yang dimaksud dengan kehati lokal adalah spesies atau sumber daya genetik tumbuhan dan satwa endemik yang hidup berkembang secara alami di daerah tertentu.

\section{Keterlibatan CSR PT. Tirta Investama Plant Solok dalam upaya pemberdayaan masyarakat di Nagari Batang Barus Kabupaten Solok}

CSR menyangkut hubungan antara perusahaan dengan masyarakat sekitarnya. CSR terkait dengan upaya pemberdayaan dan kesejahteraan masyarakat sekitar perusahaan. Menurut ISO 26000 yang dikutip Putra (2015:1): “Corporate Social Responsibility (CSR) merupakan tanggung jawab sebuah organisasi terhadap dampak keputusan yang diwujudkan dalam bentuk perilaku transparan dan etis yang sejalan dengan pembangunan berkelanjutan dan kesejahteraan masyarakat. Tanggung jawab tersebut harus mempertimbangkan harapan pemangku kepentingan, sejalan dengan hukum yang ditetapkan dan noma-norma perilaku internasional, serta terintegrasi dengan organisasi secara menyeluruh.” 5

Perusahaan yang telah meyakini CSR sebagai suatu kewajiban bagi perusahaan, maka dengan sendirinya perusahaan telah melaksanakan investasi sosial. Pembangunan pada hakekatnya merupakan suatu proses perubahan yang berlangsung secara sadar, terencana dan berkelanjutan. Pembangu-nan suatu negara tidak hanya menjadi tanggung jawab pemerintah, akan tetapi juga tanggung jawab sektor swasta dan masyarakat. Dalam hal ini, partisipasi dari masyarakat sangat dibutuhkan sebagai sarana checks and balances bagi pemerintah, mengawasi

\footnotetext{
5 Retnaningsih, Hartini. 2015. "Permasalahan Corporate Social Responsibility (Csr) Dalam Rangka Pemberdayaan Masyarakat The Problem on Corporate Social Responsibility (CSR) for Community Empowerment." Aspirasi 6(2): 177-88.
} 
penyalahgunaan kewe-nangan sosial pemerintah, serta mempengaruhi kebijakan pemerintah. ${ }^{6}$

Penting untuk melihat sejauhmana implementasi dari program pengembangan masyarakat (Community Development) dalam kaitannya dengan partisipasi seluruh stakeholder yang pada akhirnya membawa dampak bagi komunitas perdesaan. Pada dasarnya keberhasilan suatu program CSR, salah satunya berkaitan dengan bagaimana program CSR tersebut dapat berpengaruh secara signifikan dan pada akhirnya membawa dampak positif terhadap kehidupan komunitas disekitar wilayah perusahaan. ${ }^{7}$

PKBI Sumatera Barat didukung oleh CSR AQUA pabrik Solok melakukan pemberdayaan di Nagari Batang Barus semenjak tahun 2014. Perkumpulan Keluarga Berencana Indonesia (PKBI) adalah Lembaga Swadaya Masyarakat (LSM) yang bergerak dibidang kesehatan reproduksi dan keluarga berencana didirikan di Indonesia semenjak tahun 1957 dan di Sumatera Barat tahun 1974 yang bertujuan untuk mewujudkan keluarga bertanggung jawab dengan nilai dasar kerelawanan, kepeloporan, professional dan kemandirian. Dan semenjak Sejak Tahun 1978 PKBI telah melaksanakan bermacam program pemberdayaan masyarakat.

Tujuan yang hendak dicapai oleh PKBI Sumatera Barat dapat diketahui dengan menelaah visi dan misinya.Visi PKBI adalah terwujudnya masyarakat yang dapat memenuhi kebutuhan serta hak-hak kesehatan reproduksi dan seksual yang berkesetaraan dan berkeadilan jender.Visi tersebut dicapai denganmelaksanakan 3 misi.Ketiga misi diatas memperlihatkan keterlibatan PKBI Sumatera Barat dalam pemberdayaan masyarakat di Sumatera Barat. Pertama adalah memberdayakan masyarakat dan keluarga agar warganya mampu mengambil keputusan terbaik bagi

\footnotetext{
6 Wahyuningrum, Yuniarti, Irwan Noor, dan Abdul Wachid. "Pengaruh Program Corporate Social Responsibility Terhadap Penigkatan Pemberdayaan Masyarakat (Studi pada Implementasi CSR PT . Amerta Indah Otsuka Desa Pacarkeling Kecamatan Kejayan Kabupaten Pasuruan ).” Jurnal Administrasi Publik (JAP) 1(5): 109-15.

7 Isma Rosyida, Fredian Tonny Nasdian. 2011. "Partisipasi Masyarakat Dan Stakeholder Dalam Penyelenggaraan Program Corporate Social Responsibility ( Csr ) Dan Dampaknya Terhadap Komunitas Perdesaan Society and Stakeholder Participation in Corporate Social Responsibility ( CSR ) Program and the Impact.” Jurnal Transdisiplin Sosiologi, Komunikasi, dan Ekologi Manusia 05(01): 51-70.
} 
dirinya dan berperilaku bertanggung jawab dalam hal kesehatan reproduksi.Kedua, mengembangkan pusat informasi, edukasi dan konseling serta pelayanan keluarga berencana yang berkualitas.Ketiga, melakukan advokasi di semua tingkatan organisasi kepada para pengambil kebijakan untuk menjamin pemenuhan hak-hak kesehatan seksual dan reproduksi.

Bentuk kerjasama antara PKBI dengan PT. Tirta Investama Plant Solok dilaksanakan melalui Kontrak yang di lakukan setiap program yang dilakukan oleh kedua belah pihak, dimana PKBI sebagai vendor melaksanakan kegiatan pemberdayaan masyarakat sesuai aturan yang dituangkan didalam Danone's code of coduct for businees partners. Pada tahun pertama dan kedua, PKBI Sumatera Barat melakukan pemberdayaan pada program air bersih, sedangkan tahun ketiga dan keempat fokus pemberdayaan pada program Peningkatan Perilaku Hidup Bersih dan Sehat (PHBS) dengan Pendekatan Sanitasi Total Berbasis Masyarakat (STBM Pada tahun keempat, daerah sasaran program STBM ini di Andaleh Dusun IV Jorong Kayu Jao Nagari Batang Barus, durasi waktu pelaksanaan berkisar selama 9 bulan dari bulan Mei 2017 sampai Februari 2018.

Melalui pemberdayaan serta dukungan dari pemerintah daerah dan pemerintah nagari, hal ini menghasilkan komunitas yang sadar kesehatan terbukti dari adanya dokumen kawasan yang bebas buang air besar sembarangan tahun 2017 dan $100 \%$ masyarakat telah memiliki jamban sehat. Meskipun cakupan pemberdayaan dilakukan di tingkat dusun, tetapi berpengaruh terhadap pengambil kebijakan dan komunitas lain, dilihat dari meningkatnya persentase akses jamban Nagari Batang Barus dari sebelum adanya program STBM.

Kearifan lokal jika dikaitkan dengan pe-laksanaan CSR adalah perusahaan tetap mela-kukan kegiatan perusahaannya dengan tetap mengijinkan dan mengembangkan budaya, adat istiadat serta kebiasaan masyarakat setempat.Sebagai bentuk komunitas lokal yaitu upaya untuk menciptakan social value yang bermakna bagi masyarakat dan perusahaan demi tercapai-nya pelaksanaan CSR.Melalui interaksi tersebut kemudian dapat tercipta hubungan timbal balik yang saling pengertian dan memberikan keun-tungan bagi 
keduanya.CSR perusahaan banyakdilakukan dengan pola Community Development. ${ }^{8}$

Bentuk keterlibatan CSR PT. Tirta Investama Pabrik Solok dalam upaya pemberdayaan masyarakat Batang Barus adalah melalui kegiatan Sanitasi Total Berbasis Masyarakat (STBM) adalah pendekatan untuk mengubah perilaku higienes dan sanitasi melaluipemberdayaan masyarakat dengan metode pemicuan. STBM ini merupakan program pemerintah berdasarkan Pada Undang-Undang Peraturan Menteri Kesehatan Republik Indonesia Nomor 3 Tahun 2014 Tentang Sanitasi Total Berbasis Masyarakat. Permenkes ini sebagai pengganti Keputusan Menteri Kesehatan Nomor 852/ Menkes / SK/ IX/ 2008 tentang Strategi Nasional Sanitasi Total Berbasis Masyarakat (STBM), kemudian istilah ini lah yang di adopsi oleh PKBI dalam melaksanakan kegiatan pemberdayaan di Nagari Batang Barus melalui dukungan dari CSR PT. Tirta Investama Plant Solok.

\section{F. PENUTUP}

Berdasarkan hasil penelitian dan pembahasan terhadap permasalahan dalam kaitannya dengan tanggung jawab sosial perusahaan (corporate social responsibility) pada PT. Tirta Investama Plant Solok adalah:

1. Dalam pelaksanaan CSR langkah strategis yang di lakukan oleh PT. Tirta Investama Danone Aqua dipercayakan kepada NGO yakitu Mitra Perkumpulan Keluarga Berencana Indonesia (PKBI) Provinsi Sumatera Barat dan Yayasan Field Indonesia sejak Tahun 2014 melalui lembaga ini lah CSR di laksanakan, dalam konteks ini NGO di artikan sebagai pelaksana, pendamping, pembimbing, dan pengontrol program CSR agar telaksana dan tujuan tercapai, bentuk kegiatannya di bidang sosial: Program pemetaan sosial, Pembuatan fasilitas air bersih dan sanitasi, Seminar Reproduksi remaja di Nagari Batang Barus. Bidang ekonomi: Program sekolah lapangan alpukat, berbagai program donasi di tiga Nagari Batang Barus, pemberdayaan ekonomi masyarakat melalui kader posyandu, sedangkan Bidang lingkungan: membangun Taman

\footnotetext{
${ }^{8}$ Antonius Suhadi, AR. Febrian, Sri Turatmiyah. 2014. "Model Corporate Social Responsibility (Csr) Perusahaan Tambang Batubara Di Kabupaten Lahat Terhadap Pemberdayaan Masyarakat Berbasis Kearifan Lokal.” Jurnal Dinamika Hukum 14(1): 72-82.
} 
Keanekaragaman Hayati (KEHATI)dan Program Sanitasi Total Berbasis Masyarakat.

2. Keterlibatan CSR PT. Tirta Investama dalam pemberdayaan Masyarakat di Nagari Batang Barus adalah melalui program Sanitasi Total Berbasis Masyarakat (STBM). PKBI sebagai vendor melaksanakan kegiatan pemberdayaan masyarakat sesuai aturan yang dituangkan didalam Danone's code of coduct for businees partners. Perjanjian dilakasanakan melalui sebuah Purchase Order (PO) berupa surat perintah bayar dari PT. Tirta Investama Plant Solok kepada Vendor (PKBI) selanjutnya di keluarkan Surat perintah kerja yang berisikan pernjanjian untuk segera melakukan program STBM. Keterlibatan PKBI Sumatera Barat di Nagari Batang Barus tidak semata-mata menjalankan proyek kerjasama tetapi juga telah berhasil membuat sebuah pacta integritas Surat Keputusan Deklarasi bebas buang air besar sembarangan (BBABS) yang di tanda tangani oleh Wali Nagari dan komite sanitasi di tiap jorong dan segenap pemangku kepentingan di Nagari Batang Barus.

\section{DAFTAR PUSTAKA}

Ali, Zainudin. 2010. Metode Penelitian Hukum. Jakarta: Sinar Grafika.

Annisa Nurbaety, Rina Ratnasih, Hikmat Ramdan. 2005. "ANALISIS

IMPLEMENTASI CORPORATE SOCIAL RESPONSIBILITY PT BIO FARMA DI DESA SUKAMULYA KABUPATEN SUKABUMI.” Jurnal Sosioteknologi 14(2): 141-53.

Antonius Suhadi, AR. Febrian, Sri Turatmiyah. 2014. "MODEL CORPORATE SOCIAL RESPONSIBILITY (CSR) PERUSAHAAN TAMBANG BATUBARA DI KABUPATEN LAHAT TERHADAP PEMBERDAYAAN MASYARAKAT BERBASIS KEARIFAN LOKAL." Jurnal Dinamika Hukum 14(1): 72-82.

DBKLPM. 2011. Pedoman CSR Lingkungan Hidup. Jakarta.

Firdaus. 2017. "Normativiitas Corporate Social Responsibility Antara Idealita Dan Realitas.” Jurnal Ilmu Hukum 4(1). 
Hasan, Umar. 2014. "Kewajiban Corporate Social Responsibility (CSR) Dilihat Dari Perspektif Hukum”, Majalah Hukum Forum Akademika.” (1).

I Made Arya Agastya Pramana, A.A. Gd Agung Artha Kusuma. 2016. "PENGARUH CORPORATE SOCIAL RESPONSIBILITY TERHADAP PERILAKU WORD OF MOUTH POSITIF DAN CITRA MEREK AQUA.” Jurnal Manajemen Unud 5(12): 8107-33.

Isma Rosyida, Fredian Tonny Nasdian. 2011. "PARTISIPASI MASYARAKAT DAN STAKEHOLDER DALAM PENYELENGGARAAN PROGRAM CORPORATE SOCIAL RESPONSIBILITY ( CSR ) DAN DAMPAKNYA TERHADAP KOMUNITAS PERDESAAN Society and Stakeholder Participation in Corporate Social Responsibility ( CSR ) Program and the Impact.” Jurnal Transdisiplin Sosiologi, Komunikasi, dan Ekologi Manusia 05(01): 51-70.

Marnelly, T Romi. 2012. “CORPORATE SOCIAL RESPONSIBILITY (CSR): Tinjauan Teori dan Praktek di Indonesia.” JURNAL APLIKASI BISNIS 2(2): 49-59.

Pranoto, Asa Ria, dan Dede Yusuf. 2014. "Program CSR Berbasis Pemberdayaan Masyarakat Menuju Kemandirian Ekonomi Pasca Tambang di Desa Sarijaya." Jurnal Ilmu Sosial dan Ilmu Politik 18(1): 39-50.

Retnaningsih, Hartini. 2015. "PERMASALAHAN CORPORATE SOCIAL RESPONSIBILITY (CSR) DALAM RANGKA PEMBERDAYAAN MASYARAKAT The Problem on Corporate Social Responsibility (CSR) for Community Empowerment.” Aspirasi 6(2): 177-88.

Siregar, Chairil N. 2007. “ANALISIS SOSIOLOGIS TERHADAP IMPLEMENTASI CORPORATE SOCIAL RESPONSIBILITY PADA MASYARAKAT INDONESIA.” Jurnal Sosioteknologi 6(12): 285-88.

Soerjono Soekanto, Purnadi Purbacaraka. 1979. Perihal Penelitian Hukum. Bandung: Alumni.

Untung, Hendrik Budi. 2008. Corporate Social Responsbility. Jakarta: Sinar Grafika. 
Pemberdayaan Masyarakat Sebagai Wujud Tanggung Jawab Sosial Perusahaan (Studi Kasus Pt. Tirta Investama Plant Solok) Di Nagari Batang Barus Kabupaten Solok Yulia Risa

$e-I S S N: 2621-4105$

Wahyuningrum, Yuniarti, Irwan Noor, dan Abdul Wachid. "PENGARUH PROGRAM CORPORATE SOCIAL RESPONSIBILITY TERHADAP PENIGKATAN PEMBERDAYAAN MASYARAKAT ( Studi pada Implementasi CSR PT . Amerta Indah Otsuka Desa Pacarkeling Kecamatan Kejayan Kabupaten Pasuruan ).” Jurnal Administrasi Publik (JAP) 1(5): 109_ 15.

Zain, Qurratie. 2015. "Collaboration Strategy dalam Implementasi Corporate Social Responsibility (CSR): Studi Kasus Aqua Danone Klaten.” Jurnal Hubungan Internasiona VIII(2): 81-98. 